Commonwealth which are not already preparing their own annual volumes of abstracts.

The geological liaison officer serves on a number of committees concerned with mineral resources, their development and utilization. The officer, as a specialist on the subject of geology and mineral resources, also acts in close liaison with the scientific liaison officers of the other Commonwealth countries, and at the same time close liaison is maintained.with the Ministry of Materials, Department of Scientific and Industrial Research and other Ministries in Great Britain which are interested in the mineral resources and their availability throughout the Commonwealth. Reports and accounts of meetings and conferences concerned with geology and mineral resources are also prepared and circulated to the Commonwealth countries.

Close contact is maintained by the Geological Liaison. Office with the Colonial Geological Surveys Directorate, as the two organizations are in a sense complementary; the latter links all the Colonial Geological Surveys, while the former is an attempt to link, in a less formal way, the Commonwealth Geological Surveys. The Geological Liaison Office is now charged, as a result of recommendations by the British Scientific Official Conference in Australia, with the formation of Commonwealth collaboration on geophysical prospecting, and the beneficiation and utilization of low-grade ores. The Office is now firmly established as an intrinsic part of the British Commonwealth Scientific Office, and, as an experiment in a purely Commonwealth organization, appears to be functioning with some measure of success.

\section{RECORDING OF RESEARCH AND ITS PATENT ASPECTS}

$\mathrm{M}$

ANY research workers, more usually the younger ones, dislike keeping adequate records of their investigations, but the fact has to be faced that the keeping of proper records is probably much more important, and a much less simple obvious matter, than is often supposed. Various aspects of the subject were discussed last year by a joint committee of the Franklin Institute and of the American Patent Law Association in a programme entitled "Who is the First Inventor ?" ; and further consideration has been given in a recent timely and interesting article by J. G. Jackson, on "Records of Research" ( $J$. Franklin Inst., 254, 355; 1952).

There are, of course, several sound reasons for keeping good records, many of which are sufficiently obvious without undue elaboration. (a) Avoidance of duplication, especially in prolonged research, when problems may again crop up that have been already studied and not recorded. (b) Taking full advantage of negative results, which also may prevent duplication if properly noted at the time. (c) Assisting the development of a fundamental approach, for very often at the start the workers are somewhat in the dark, or are taking part in one small section of a comprehensive programme, so that they think their results are relatively unimportant and not worth reporting; but such data later on prove essential in developing a theory or fundamental approach. (d) Publication; when work is published or reported at a meeting, supplementary questions arise which cannot be answered because full data have not been recorded. (e) Patent requirements; for example, insufficient record prevents the inventor from establishing that he was the first inventor, and it may thus happen that the company which developed the subject-matter may be forced to take a licence under someone else's patent.

The very minimum of information that should be recorded is the date of commencement of work, by whom it is done, detailed account of the work (with date of each important step) and the results. Such recording may often be the proper function of the research director or group supervisor. For patent purposes it is absolutely essential that provision be made for corroboration, and this is discussed at some length by Mr. Jackson. Some useful practical notes on this part of the subject can be found elsewhere ${ }^{1,2}$,

Certain milestones in connexion with research in industry should be formalized, to enable firms to determine the progress being made and the status at each stage. These formal steps are very helpful in tying together various records for patent purposes; and assigning project numbers is, for the same reason, of great assistance.

Several valuable suggestions on the keeping of laboratory notebooks are given : step-by-step records in order of time; making of sketches and drawings ; issuing a specification on an item under development before it is standardized (which constitutes a valuable record of research) ; photographs and samples ; and codes and abbreviations. These last-named may often be the cause of much trouble and confusion, some curious examples of which are given. Special records may sometimes be required from the point of view of patents, on which much useful advice is provided. Finally, it is pointed out that publications perform certain functions as research records, and have a special significance in patent matters.

${ }^{1}$ Kapp, "Laboratory Notebooks", 33 JPOS (J. Pat. Off. Soc., 502 (1951). "Tuska, "Patent Notes for Engineers", 3rd edit. (Radio Corp.
America, 1947).

\section{ELECTRONIC DIGITAL COMPUTERS}

\section{CONFERENCE IN THE UNITED STATES}

IN 1950 a meeting was held in Atlantic City, N.J., to discuss electron tubes for computers. The meeting was initiated by Dr. A. L. Samuel, as representative of the Research Development Board, and was sponsored by the American Institute of Electrical Engineers and the Institute of Radio Engineers. 'The success of this initial meeting led Prof. J. G. Brainerd to suggest the formation of a joint computer conference committee between these two last-named bodies in order to consider whether further meetings should be held and, if so, on what subjects. It was decided that the subjects which required urgent attention were electronic digital computers, input and output equipment, high-speed memory and choice of number system. Accordingly, the joint conference held in Philadelphia, Penn., during December 10-12, 1951, dealt with the first topic, and a recent conference, during December 10-12, 1952, at New York City, was concerned with input and output equipment.

The 1951 meeting, at which the Association for Computing Machinery also co-operated, attracted an attendance of 877 members, and the eighteen papers 
and discussions that were presented have recently been published*. Ten different large-scale electronic computers of varying design and performance are separately described. These are the UNIVAC, ORDVAC, EDSAC, SEAC, ERA 1101, Burroughs Laboratory, Whirlwind I and the University of Manchester computers, and the IBM card-programmed and the Mark III electronic calculators. In other papers detailed operating and component experience on certain of these instruments is discussed. In addition, a report on the use of computing machines in aircraft engineering is given by C. R. Strong, of the Douglas Aircraft Co., the seven digital computers designed and built by the Bell Telephone Co. are described by E. G. Andrews, and the application of transistors to digital computation is discussed by J. H. Felker.

Finally, a summary of the present status and future trends of digital computers is given by $\mathrm{J} . \mathrm{W}$. Forrester, in which he states that it is clear that the pioneering days are over and that enough experience of the various models has now been gained to judge the adequacy of the designs. Though there are quite definite lines of development - for example, towards machines of still higher speed-it is worth while to note the concluding sentences of Mr. Forrester's summary which aptly summed up the position at the end of 1951: "Machine speed has increased by several orders of magnitude over the last ten years. In the future we can perhaps get another decade in speed, but I doubt that more can be accomplished without a fundamentally new type of computer. The great steps in the near future will be in the direction of simplification without losing performance. It seems clear that the complexity of computers can and must be reduced."

* Review of Electronic Digital Computers: Joint AIEE-IRE Gomputer Conference. Papers and Discussions presented at the Joint AIEE-IRE Computer Conference, Philadelphia, December 10-12, 1951. Pp. 114. (Amer. Inst. Elec. Eng., 33 West 39th Street, New York 18, 1952.) 3.50 dollars.

\section{PRODUCTION OF HIGH VACUA BY IONIZATION}

A LITTLE while ago, Dr. A. von Engel directed attention to the method of obtaining high vacua by ionization (Vacuum, 1, No. 4; Oct. $195 \mathrm{I}$ ); it is therefore of interest to note that a discussion of the principles and limitations of such pumping action, together with a description of an electronic pump which was the subject of a German patent in 1943, is given in a paper by $\mathrm{H}$. Schwarz*.

The idea of obtaining high vacua by ionization is, of course, quite old and well known, and the clean-up, that is, absorption of gases or vapours, in an electrical discharge is a common experience and fairly well understood. Dr. Schwarz, however, shows theoretically that it is not possible, even under the most favourable conditions, to construct a high-vacuum pump with reasonable dimensions utilizing a normal D.C. gas discharge. A real pumping action can only result when there is such a high ion-current that the number of ionized gas molecules transported in one direction is greater than the number of gas molecules diffusing back in the

- Centro Brasileiro de Pesquisas Fisicas. Notas de Fisica No. 5 : Methods of obtaining High Vacuum by Ionization; Construction of Centro Brasileiro de Pesquisas Fisicas, 1952.) opposite direction. It is necessary, therefore, to increase the path of the electrons without increasing the length of the tube, and this may be accomplished either by making the electrons oscillate on screw paths about the tube axis, or by using an external magnetic field which forces the electrons to travel in spiral paths within a cylindrical electrode system, as in the magnetron or cyclotron.

The model of an electronic pump which Dr. Schwarz describes consists of an incandescent cathode, a ring-shaped anode at about $2,000 \mathrm{~V}$. and a third annular electrode at cathode potential. The 10-mA. electron current is kept oscillating through the anode, and a magnetic field parallel to the tube axis keeps the electrons on spiral paths at the centre of the tube away from the anode. Special arrangements are made to remove absorbed gas from the glass walls of the tube and to prevent ions from diffusing back into the high-vacuum side. As a test of the pump, a volume of half a litre was pumped down from a pressure of $10^{-3}$ to $10^{-5} \mathrm{~mm}$. of mercury in less than one second.

\section{CULTIVATION OF SULPHATE- REDUCING BACTERIA}

\section{By JOY P. GROSSMAN and DR. JOHN R. POSTGATE \\ Chemical Research Laboratory, Teddington, Middlesex}

GTUDIES on the bacteriology and biochemistry of $D$ the sulphate-reducing bacteria have long been obscured by inconsistencies in the behaviour of these organisms. For example, tests on the ability of a single strain to utilize various sources of carbon may give different results on different occasions; subcultures sometimes fail to grow, or grow with a very long lag, for no obvious reason; dilution counts on a motile and obviously healthy population indicate that rarely more than 10 per cent and often as little as 0.01 per cent of these cells are apparently viable; strains grown with excess of ferrous ions in the medium often do not grow readily without this; and so on. Though the capriciousness of these bacteria has not often been described explicitly in the literature, it is common experience among workers in the field. The observations described below to some extent clarify the situation. Since they bear closely on the work of other laboratories studying these bacteria, and since they have required a re-assessment of earlier work in this laboratory, we have felt that this preliminary report is desirable.

The fundamental observation, that reducing agents stimulate the activities of these bacteria, has been reported by many sources, including this laboratory ${ }^{1-4}$, and the importance of a negative redox potential for their effect in anaerobic corrosion was emphasized by Starkey and Wight ${ }^{5}$.

Methods. Strains of Desulphovibrio desulphuricans were cultured at $30^{\circ} \mathrm{C}$. in anæerobic jars containing hydrogen plus 5 per cent carbon dioxide or in sealed test-tubes containing a plug soaked in pyrogallol with strong sodium carbonate. For normal subcultures a 1/100 dilution of a grown culture was made into fresh medium. Dilution counts were performed in duplicate by making serial $1 / 10$ dilutions in the appropriate medium using a fresh pipette at each stage. Direct 